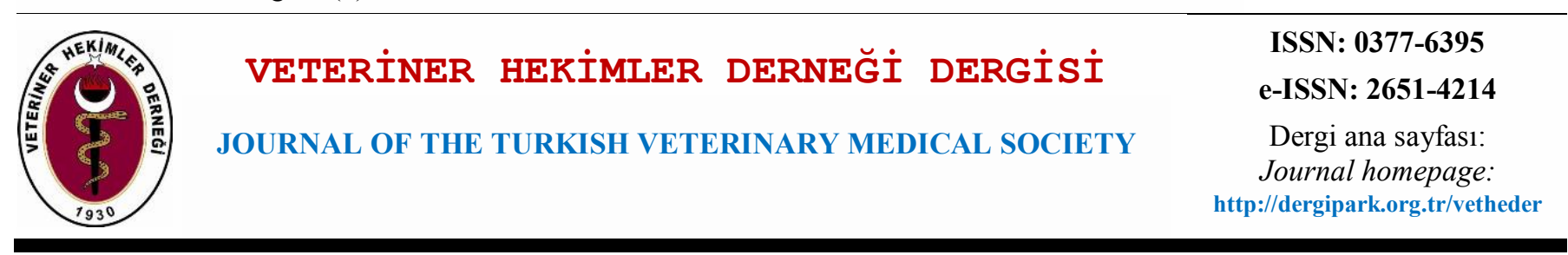

\title{
Fırat Üniversitesi Veteriner Fakültesi Dergisi üzerine tarihsel bir inceleme***
}

\author{
Rahşan ÖZEN ${ }^{1, a^{*}}$ \\ ${ }^{1}$ Fırat Üniversitesi Veteriner Fakültesi, Veteriner Hekimliği Tarihi ve Deontoloji Anabilim Dalı, Elazığ, Türkiye \\ ORCID: 0000-0001-5788-0289 a
}

\author{
MAKALE BILLGisi / \\ ARTICLE \\ INFORMATION: \\ Geliş / Received: \\ 01 Şubat 19 \\ 01 February 19 \\ Kabul / Accepted: \\ 14 Mart 19 \\ 14 March 19 \\ Anahtar Sözcükler: \\ Fırat Üniversitesi \\ Veteriner Fakültesi \\ Dergisi, \\ Süreli yayın, \\ Veteriner hekimliği \\ tarihi
}

Keywords:

The Journal of Firat

University Veterinary

Faculty,

Periodical,

History of veterinary

medicine
ÖZET:

Bu çalışma, Fırat Üniversitesi Veteriner Fakültesi Dergisini bilim dünyasına tanıtmak ve veteriner hekimliği süreli yayınlar tarihçesine katkı yapmak amacıyla hazırlanmıştır. Çalışmanın materyalini, Fırat Üniversitesi Veteriner Fakültesi Veteriner Hekimliği Tarihi ve Deontoloji Ana Bilim Dalı Arşivinde bulunan, Fırat Üniversitesi Veteriner Fakültesi Dergileri oluşturmuştur. Dergide, 1974-1982 yılları arasında yayımlanan tüm bilimsel çalışmalar anabilim dallarına ve yayın dillerine göre sınıflandırılmıştır. Dergide, 109 araştırma makalesi, 29 derleme ve iki çeviri olmak üzere toplam 140 bilimsel çalışma saptanmıştır. Bu çalışmaların bilim alanlarına göre dağılımı incelendiğinde; Dölerme ve Sun'i Tohumlama ve Genetik alanlarında hiç çalışma olmadığı, en fazla sayıda çalışmanın ise Zootekni alanından olduğu görülmüștür. Ayrıca Dergide, bilimsel çalıșmalar dışında, bazı sayılarda "Akademik Haberler” başlığı altında, akademik yükseltmeler, görevlendirmeler, kongre katılımları, açılış, mezuniyet töreni, kitap tanıtımı, tez özetleri vb. duyurulara da ulaşılmış; yurtdışında basılan dergilerin Türkçeye çevrilen özetleri yer almıştır.Sonuç olarak; Fırat Üniversitesi Veteriner Fakültesi Dergisinin, başta Doğu Anadolu Bölgesinin ve Türkiye'nin hayvancılık sorunlarına yönelik yürütülmüş bilimsel çalışmaların bir kısmına ev sahipliği yaptığı; yayın hayatı süresince akademik çalışmalar dışında eğitsel ve mesleki bir takım yazılara da yer vermek suretiyle arșiv niteliği tașıyan bir kaynak olduğu ileri sürülebilir.

\section{A historical research on the Journal of Furat University Veterinary Faculty}

ABSTRACT:

This study is aimed at introducing the Journal of Frrat University Veterinary Faculty to the scientific community and at contributing to the history of veterinary periodicals. The study material comprised all published issues of the Journal, archived by the Department of the History of Veterinary Medicine and Deontology of, Firat University Veterinary Faculty. The scientific researches published in the Journal between the years 1974-1982 were classified according to scientific discipline, and language of publication. It was determined that a total of 140 scientific researches, including 109 research articles, 29 reviews and 2 translated manuscripts, were published in the Journal. The evaluation of manuscripts revealed that while no research was published about reproduction-artificial insemination and genetics, most of the researches published in the Journal were related to zootechnics. Furthermore, apart from scientific research, notifications of academic promotions, assignments, congress participations, opening events, and graduation ceremonies, as well as book introductions, thesis summaries, and Turkish translations of excepts from foreign journals, etc. were also published under the title of "Academic News". In result, the Journal of Firat University Veterinary Faculty communicated to its audience many scientific studies that addressed the problems encountered in the livestock sector in Eastern Anatolia and Turkey. Throughout its publication period, the Journal also having published articles related to educational and professional topics, apart from academic research, suggests that the Journal also serves as an archival source.

How to cite this article: Özen R: Frrat Üniversitesi Veteriner Fakültesi Dergisi üzerine tarihsel bir inceleme. Vet Hekim Der Derg, 90 (2): $98-104$, 2019. DOI: 10.33188 /vetheder.520826

*Sorumlu yazar/Corresponding author

eposta adresi/e-mail address: rahsanozen@hotmail.com

**Bu çalışma 4-6 Ekim 2018'de Elazı̆̆g' da VI. Veteriner Hekimliği ve Mesleki Etik Sempozyumunda sözlü bildiri olarak sunulmuştur. 


\section{Giriş}

Avrupa'da matbaanın icadını takip eden dönemde, basılı kitap sayısı hızla artmış; 17’nci yüzyılın başından itibaren de süreli yayınlar yayım hayatına girmeye başlamıştır (9).

Dünya'da veteriner hekimliği okullarının açılmaya başlamasının ardından mesleki yazılar tarım dergilerinde basılmaya devam etmiş; ilk bilimsel veteriner hekimliği dergisi 1788 yılında Almanya'da çıkarılmıştır $(6,10)$.

Osmanlı Devletinde ilk bilimsel ve mesleki dergilerin yayımı ancak 19'uncu yüzyılın ortalarından sonra başlamış; bu dergilerin bir kısmının kişisel çabalarla, bir kısmının da ilmi ve mesleki dernekler ile çeşitli devlet kurumları tarafindan çıkarıldı ğı anlaşılmıştır (8).

Türkiye'de veteriner hekimliği alanında bilimsel nitelik taşıyan ilk süreli yayın, veteriner hekimliği ve ziraat konularını birlikte ele alan ve 1 Mayıs 1880 tarihinde yayınlanmaya başlanan "Vasıta-i Servet" dir $(4,6,10)$. Ülkemizde tümüyle veteriner hekimliği konularını içeren ilk mesleki dergi ise 14 Eylül 1908 yayımı başlanan "Мecmua-i Fünûni Baytariye"dir (2,3,10). Bu dergileri, "Askeri Tibbi Baytarî, Mecmûası" (1923), "Baytarî Mecmûa" (1923), "Türk Baytarlar Cemiyeti Mecmûası” (1930) gibi mesleki ve bilim dergileri izlemiştir $(5,6,10)$.

Veteriner hekimliği alanındaki yayın faaliyetleri, bu alandaki kurum ve sivil toplum örgütlerinin yapılanmasına paralel olarak artmış; faaliyete başlayan hemen hemen her fakülte, enstitü, dernek vb. çalışmalarını daha geniş kitlelere ulaştırabilmek, mesleğin bilimsel ve sosyal gelişimine katkı sağlamak için bir dergi çıkarma yoluna gitmiştir (9).

Türkiye'de Veteriner Fakülteleri tarafindan çıkarılan ilk dergi, 1954 yılında Ankara Üniversitesi Veteriner Fakültesi tarafından yayınlanmaya başlayan ve yalnız bilimsel konularda çalışmaların yer aldığı Veteriner Fakültesi Dergisi'dir (6).

Türkiye'nin ikinci veteriner Fakültesi, Elazığ'da 1970 yılında Ankara Üniversitesi Elazığ Veteriner Fakültesi adı ile açılmış ${ }^{* *}, 1975$ yılında Fırat Üniversitesinin kurulmasının ardından, Fırat Üniversitesi Veteriner Fakültesi adını almıştır $^{* * *}$. Fırat Üniversitesi Veteriner Fakültesi Dergisi, 1974 yılında Ankara Üniversitesi Elazığ Veteriner Fakültesi Dergisi adıyla yayın hayatına başlayan ve Türkiye'de Veteriner Fakülteleri tarafindan çıkarılmaya başlanan ikinci süreli yayındır. Bu dergi aynı zamanda Fırat Üniversitesinin de ilk süreli yayınıdır.

Çalışma, Fırat Üniversitesi Veteriner Fakültesi Dergisini tanıtmak ve veteriner hekimliği süreli yayınlar tarihçesine katkı yapmak amacıyla hazırlanmıştır.

\section{Gerec ve Yöntem}

Çalışmanın materyalini Fırat Üniversitesi Veteriner Fakültesi Veteriner Hekimliği Tarihi ve Deontoloji Anabilim Dalı Arşivinde bulunan Fırat Üniversitesi Veteriner Fakültesi Dergileri oluşturmuştur. Dergide, 1974-1982 y1lları arasında yedi cilt ve toplam onbeş sayıda yayımlanan tüm bilimsel çalışmalar; her ana bilim dalına göre Türkçe ve yabancı dilde Araştırma Makalesi, Derleme ve Çeviri olarak ayrılmış; veriler tablolar halinde gösterilerek içerik analizi ile değerlendirilmiştir. Dergide yayımlanan bilimsel çalışma sayısı hesaplanırken; çok yazarlı çalışmalarda aynı makalenin birden fazla sayılmaması için ilk yazar esas alınmış, ilk yazarın bilim alanına göre değerlendirme yapılmıştır. Orijinal belgelerin künye bilgileri dipnotlarda gösterilmiştir. Çalışma medikal tarih araştırmalarında uygulanan analiz ve sentez yöntemleriyle değerlendirilmiş; konu, kronolojik olarak ele alınmıştır.

\footnotetext{
** 14 Nisan 1970 tarih ve 1253 sayılı Ankara Üniversitesi Kuruluş Kadroları hakkındaki 5239 sayılı Kanuna ek Elâzığ Veteriner Fakültesi Kuruluş kadroları hakkında Kanun 22 Nisan 1970 gün ve 13478 sayılı Resmi Gazete.

*** 1 Nisan 1975 tarih ve 1873 sayılı Dört Üniversite Kurulması Hakkında Kanun 11 Nisan 1975 tarih ve 15205 sayılı Resmi Gazete.
} 


\section{Bulgular}

Türkiye'nin ikinci veteriner fakültesi, Ankara Üniversitesi Elazığ Veteriner Fakültesinin yayın organı olan ve Ankara Üniversitesi Elazığ Veteriner Fakültesi Dergisi adıyla yayın hayatına başlayan derginin amacı, 1974 yılında basılan ilk sayısında Dergi imzası ile "Başlarken" adı altında açıklanmıştır.

“ Cumhuriyetimizin 50. Yılında yayın hayatına girmiş olmanın mutluluğu içindeyiz. Fakültemiz, hayvancılık yönünden, ülkemizin en zengin potansiyele sahip bir bölgesinde çok isabetli bir kararla açllarak 1970-1971 ders yılında ögretime başlamış bulunuyor.

Yurdumuzun batısı ile doğusu arasındaki dengesizlik yüzyllların ihmalinden doğmaktadır. Hükümetlerimiz bu seviye farkını, en klsa zamanda, ortadan kaldırmak için ciddi tedbirler almak ve etkili girişimlerde bulunmak zorundadır. Bu çalışmalarda kuruluş halinde olan Üniversitelerin önemli katkıları olacağı açıktır.

Dergimiz, bölgenin hayvancıllk sorunlarını ve Fakültemizin akademik faaliyetlerini dile getirmeye çalışacak ilmî bir organdır. Doğu Anadolu'da hayvancılıkla ilgili, henüz ele alınmamış, bir çok inceleme ve araştırma konusu vardir.

Bugün her alanda üretim, ilmî araştırmaların sonuçları göz önünde bulundurularak yapılmaktadır. Ayrıca dlş ülkelerde yapılan araştırma verilerinin yurdumuzda olduğu gibi uygulanma olanağı da söz konusu olamaz. Çevre şartları, ekonomik ve sosyal durum göz önünde bulundurularak orijinal araştırmalar yapmak ve yetiştiricilerin uygulamasina sunmak görevimiz olmalıdır.

Türkiye Bilimsel ve Teknik Araştırma Kurumu ve Devlet Plânlama Teşkilâtı Doğu illeri hayvancılı̆̆ını kapsayan projeleri öncelikle desteklemeli, teşvik etmelidirler.

İlgili kuruluşlardan gönderilecek yazllara dergimiz açıktır; onlara yer vermekten kıvanç duyacağız.

Yayın hayatına girerken eksiklerimizin hoş görüleceğini ümit eder yapıcı eleştirileri memnuniyetle karşılayacağımızı arz etmek isteriz."

Birinci cilt incelendiğinde makalelerin arkasında çalışmaların dergi yayın kuruluna geliş tarihleri görülmektedir. Makalelerden yedi adedinin 1.11.1973, iki adedinin ise 15.11.1973 tarihinde Dergi Yazı Kuruluna teslim edildiği anlaşılmaktadır. İlk sayının yazı kurulu, Prof. Dr. Mustafa Temizer, Prof. Dr. M. Mihri Mimioğlu, Prof. Dr. Halil Özcan ve Doç. Dr. Ruhi Töre tarafından oluşturulmuştur. Bu sayıda yazı işleri Prof. Dr. M. Mihri Mimioğlu tarafından yönetilmiştir. Dergi Yazı Kurullarında yer alan ve derginin ilgili sayısını yöneten kişilerin yıllara göre değiştiği görülmüştür (Tablo 1).

Tablo 1: Dergi yazı kurulunda görev alan öğretim elemanları

Table 1: Academic staff working in the Journal's editorial board

\begin{tabular}{|c|c|c|c|c|}
\hline Yil & Cilt & Sayı & Dergi Yazı Kurulu & Yazı işlerini yöneten \\
\hline \multirow[t]{2}{*}{1974} & 1 & 1 & $\begin{array}{l}\text { Prof. Dr. Mustafa Temizer, Prof. Dr. M. Mihri Mimioğlu, Prof. Dr. Halil Özcan, Doç. } \\
\text { Dr. Ruhi Töre }\end{array}$ & $\begin{array}{l}\text { Prof. Dr. M. Mihri } \\
\text { Mimioğlu }\end{array}$ \\
\hline & & 1 & Prof. Dr. Tayyip Çalışlar, Prof. Dr. Gündüz Akıncı, Doç. Dr. Ferruh Dinçer & Doç. Dr. Ferruh Dinçer \\
\hline \multirow[t]{2}{*}{1975} & 2 & 2 & Prof. Dr. Tayyip Çalışlar, Prof. Dr. Gündüz Akıncı, Doç. Dr. Ferruh Dinçer & Doç. Dr. Ferruh Dinçer \\
\hline & & 3 & Prof. Dr. Tayyip Çalışlar, Prof. Dr. Gündüz Akıncı, Doç. Dr. Ferruh Dinçer & Doç. Dr. Ferruh Dinçer \\
\hline \multirow[t]{2}{*}{1976} & 3 & 1 & Prof. Dr. Tayyip Çalışlar, Prof. Dr. Gündüz Akıncı, Doç. Dr. Ferruh Dinçer & Doç. Dr. Ferruh Dinçer \\
\hline & & $2-3$ & Prof. Dr. Tayyip Çalışlar, Doç. Dr. Metin Taşbaş, Doç. Dr. Rauf Yücel & Doç. Dr. Metin Taşbaş \\
\hline 1977 & 4 & $1-3$ & Prof. Dr. Tayyip Çalışlar, Doç. Dr. Metin Taşbaş, Doç. Dr. Rauf Yücel & Doç. Dr. Metin Taşbaş \\
\hline 1980 & 5 & 1 & $\begin{array}{l}\text { Prof. Dr.Turan Oğuz, Prof. Dr.Emin Arıtürk, Doç. Dr. Ferruh Dinçer, Doç. Dr. Asım } \\
\text { Çubukçu, Doç. Dr. Gürkan Ekingen }\end{array}$ & Doç. Dr. Ferruh Dinçer \\
\hline 1981 & 6 & $1-2$ & $\begin{array}{l}\text { Prof. Dr. Hamza Keskintepe, Doç. Dr. Yusuf Şanlı, Doç. Dr. Asım Çubukçu, Doç. } \\
\text { Dr. Rauf Can, Doç. Dr. Mehmet Kandil }\end{array}$ & Doç. Dr. Yusuf Şanlı \\
\hline 1982 & 7 & $1-2$ & $\begin{array}{l}\text { Prof. Dr. Hamza Keskintepe, Doç. Dr. Yusuf Şanlı, Doç. Dr. Asım Çubukçu, Doç. } \\
\text { Dr. Rauf Can, Doç. Dr. Mehmet Kandil }\end{array}$ & Doç. Dr. Yusuf Şanlı \\
\hline
\end{tabular}


Derginin Ankara Üniversitesi Elazı̆̆ Veteriner Fakültesi Dergisi adıyla yayım hayatına başladığı, ancak 1975 yılında Firat Üniversitesinin kurulmasıyla birlikte, 1975 yılı ikinci sayısından itibaren dergi yazı kurulunun ve Dergi adının "Fırat Üniversitesi Veteriner Fakültesi Dergisi" olarak değiştirildiği görülmektedir. İlk sayıda yayın aralıkları ile ilgili bir bilgi bulunmamakla beraber, ikinci cildin birinci sayısında (1975) "dört ayda bir yayımlanır" açılaması yer almıştır. Yayın aralıklarının dörder aylık periyotlar şeklinde belirlenmesine ve bu ibarenin dergi kapak sayfasında yer almasına rağmen, bazen iki bazen de üç sayının birlikte çıkarıldığı görülmüşsür. Derginin 1980 yılında çıkan beşinci cildin birinci sayısında "altı ayda bir yayımlanır" yazmasına rağmen bu yıl sadece bir sayı yayımlanmış, takip eden yıllarda ise ikişer sayı beraber çıkarılmıştır.

Derginin 1976 yılına ait üçüncü cildinin (2-3) numaralı sayısının dış kapağında 1977, 1977 yılına ait dördüncü cildinin (1-3) numaralı sayısının iç kapağında ise (1-2) şeklinde yazım hataları görülmektedir.

Sayfaların numaralandırılmasında da farklılıklar göze çarpmaktadır. Derginin 1975 yılına ait sayılar hariç, her sayının birden başlayarak numaralandırıldığı belirlenmiştir. Sadece, 1975 yılına ait üç sayının sayfa numaraları birbirini takip etmektedir. Dergi sayılarının sayfa sayıları, yayımlanan makale sayısına ve haberlere göre farkl1liklar göstermiştir.

Fırat Üniversitesi Veteriner Fakültesi Dergisi, "1978 ve 1979 yıllarında beklenmeyen basım güçlükleri nedeniyle" yayımlanamamış, bu açıklama beşinci cildin ilk sayısında (1980) Editör imzası ile "Okurlarımızın ve Abonelerimizin Dikkatine" başlığı altınca İngilizce, Almanca ve Fransızca olarak yer almıştır.

Dergi yayın kurulu tarafindan derginin yayım kurallarını belirleyen, “Elazığ Veteriner Fakültesi Dergisi”nde Yayınlanacak Yazllarda Aranan Şartlar" bölümü ilk sayının sonunda 12 madde halinde listelenmiştir. Onikinci maddede "Dergide yayımlanan yazıların telif ücretleri (Elazı̆̆ Veteriner Fakültesi Yayım Yönetmeliği)nde yazılı esaslara göre ödenir." ifadesi yer almaktadır. Derginin ikinci cildinin ilk sayısından itibaren "Elazığ Veteriner Fakültesi Dergisi'nde Yayımlanacak Yazılarda Aranan Koşullar” bölümünde önemli değişiklikler yapılmış, ayrıca dergide yayımlanan yazıların ücret ve ayrı baskı konusundaki yazar hakları Üniversiteler Yayın Yönetmeliği hükümlerine tabi olmuştur. Fırat Üniversitesinin kurulmasının ardından, başlık 1975 yılında çıkan ikinci sayıda değiştirilmiş ve "Fırat Üniversitesi Veteriner Fakültesi Dergisi'nde Yayımlanacak Yazılarda Aranan Koşullar" 1977 yılına kadar değiştirilmeden yayınlanmıştır. Bu tarihten sonra çıkan dergilerde, yayım koşulları sayfaları yer almamıştır.

Dergi, dokuz yıllık yayın hayatı boyunca (1974-1982) yedi cilt ve toplam onbeş sayıdan oluşmuştur (Tablo 2).

Tablo 2: Y1llara göre cilt ve sayı dağılımı

Table 2: Volumes and numbers distribution according to years

\begin{tabular}{lll}
\hline Y11 & Cilt & Say1 \\
\hline 1974 & 1 & 1 \\
1975 & 2 & $1,2,3$ \\
1976 & 3 & $1,(2-3)$ \\
1977 & 4 & $(1-3)$ \\
1978 & - & - \\
1979 & - & - \\
1980 & 5 & 1 \\
1981 & 6 & $(1-2)$ \\
1982 & 7 & $(1-2)$ \\
\hline
\end{tabular}

Dergide, Ankara Üniversitesi Basımevinde 1974 yılında basılan ilk sayısından 1982 yılındaki son sayısına kadar, 109 araştırma makalesi (23ü İngilizce, birer Almanca ve Fransızca), 29 derleme (bir Fransızca) ve iki çeviri (Fransızca ve İngilizce) olmak üzere toplam 140 bilimsel çalışma saptanmıştır. Bu çalışmalardan 56's1 (38 Türkçe,10 İngilizce makale ve sekiz Türkçe derleme), Ankara Üniversitesi Veteriner Fakültesindeki öğretim elemanlarınca hazırlanmıştır. Ayrıca, bir makalenin Dicle Üniversitesi Tıp Fakültesi Farmakoloji ve Toksikoloji Anabilim Dalından 
(Fırat Üniversitesi Veteriner Fakültesinden geçiş yapan) bir öğretim üyesi, iki makalenin de Frrat Üniversitesi Fen Fakültesinden öğretim elemanlarınca hazırlandığı belirlenmiştir. Dergide bir adet de yurtdışından yabancı bir yazar tarafindan hazırlanmış İngilizce makale yayımlanmıştır.

Dergideki bilimsel çalışmaların bilim alanlarına göre dağılımı (Tablo 3) incelendiğinde; Dölerme ve Sun'i Tohumlama ve Genetik bilim alanlarında hiç çalışma olmadığı, en fazla sayıda (17) çalışmanın ise Zootekni alanından olduğu saptanmıştır.

Tablo 3: Bilimsel çalışmaların anabilim dalları göre dağılımı

Table 3: Distribution of scientific articles according to departments

\begin{tabular}{|c|c|c|c|c|c|c|}
\hline \multirow[b]{2}{*}{ ANABİLİM DALI } & \multicolumn{2}{|c|}{ Araştırma Makalesi } & \multicolumn{2}{|c|}{ Derleme } & \multirow[t]{2}{*}{ Çeviri } & \multirow[t]{2}{*}{ TOPLAM } \\
\hline & Türkçe & Yabanc1 Dil & Türkçe & Yabancı Dil & & \\
\hline Anatomi & - & 1 (İngilizce) & - & - & - & 1 \\
\hline Histoloji ve Embriyoloji & - & - & 1 & - & - & 1 \\
\hline Biyokimya & 3 & 2 (İngilizce) & 2 & - & - & 7 \\
\hline Fizyoloji & 1 & 1 (İngilizce) & 1 & - & - & 3 \\
\hline VHT ve Deontoloji & 2 & 3 İngilizce) & 1 & & - & 6 \\
\hline Farmakoloji ve Toksikoloji & 5 & & 6 & 1 (Fransızca) & - & 12 \\
\hline Mikrobiyoloji & 5 & 3 İngilizce) & - & - & 1 (İngilizce) & 9 \\
\hline Parazitoloji & 10 & 1 (Fransizca) & - & - & 1 (Fransizca) & 12 \\
\hline Patoloji & 5 & 2 (İngilizce) & - & - & - & 7 \\
\hline Viroloji & 5 & 1 (Almanca) & - & - & - & 6 \\
\hline Cerrahi & 8 & - & 2 & - & - & 10 \\
\hline Doğum ve Jinekoloji & 3 & - & - & - & - & 3 \\
\hline Dölerme ve Sun'i Tohumlama & - & - & - & - & - & - \\
\hline İç Hastalıkları & 4 & 1 (İngilizce) & 4 & - & - & 9 \\
\hline Hayvan Besleme ve Beslenme Hastalıkları & 3 & - & 1 & - & - & 4 \\
\hline Zootekni & 14 & 2 (İngilizce) & 1 & - & - & 17 \\
\hline Biyometri & 1 & - & - & - & - & 1 \\
\hline Genetik & - & - & - & - & - & - \\
\hline Hayvan Sağlığg Ekonomisi ve İşletmeciliği & 4 & & 4 & - & - & 8 \\
\hline Gıda Hijyeni ve Teknolojisi & 4 & - & 1 & - & - & 5 \\
\hline Su Ürünleri, Balıkçılık ve Av Hayvanları & 1 & 8 (İngilizce) & 4 & - & - & 13 \\
\hline Diğer* & 6 & - & - & - & - & 6 \\
\hline TOPLAM & 84 & 25 & 28 & 1 & 2 & 140 \\
\hline
\end{tabular}

*Veteriner Fakültesi Zooloji Bölümü, Veteriner Fakültesi Fizik Bölümü, Fen Fakültesi Zooloji Bölümü

Dergideki çalışmalardan 14 adedinin TÜBİTAK ve uluslararası kuruluşlarca desteklenen projelerinden, yedi adedinin doktora tezlerinden (dört adedi yurtdışında yapılmış tezlerden), sekiz adedinin doçentlik tezi veya doçentlik dersi sunumlarından, dört adedinin de TÜBİTAK tarafindan düzenlenen toplantılarda sunulan çalışmalardan oluştuğu görülmüştür.

Dergide, bilimsel çalışmalar dışında, bazı sayılarda "Akademik Haberler" başlığı altında, akademik yükseltmeler, görevlendirmeler, kongre katılımları, açılış, mezuniyet töreni, kitap tanıtımı, tez özetleri, anma yazısı vb. duyurulara da ulaşılmış; yurtdışında basılan dergilerin Türkçeye çevrilen özetleri yer almıştır.

Fırat Üniversitesi Veteriner Fakültesi Dergisinin son sayısı 1982 yılında çıkarılmıştır.

\section{Tartışma ve Sonuç}

Ankara Üniversitesi Elazığ Veteriner Fakültesi Dergisi adı ile yayın hayatına başlayan derginin, düzenli bir yayın periyodu olmadığı göze çarpmaktadır. Kimi yıllar, hedeflenen periyotlara uyulmuş olsa da, bazen bir yıl 
içerisinde basılması gereken sayılar tek bir sayıda, bazen iki sayıda bazen de üç sayıda birleştirilmiştir. Özen (9) Türkiye'de 1989-1998 yılları arasında yayımlanmış olan, veteriner fakülteleri ve meslek örgütleri tarafından çıkarılan dergilerin bazılarının, birkaç sayının bir arada, hatta birkaç yıl gecikme ile çıkarıldığını, Aslım ve ark. (1) Türk Veteriner Hekimleri Birliği Dergisinin yayın aralıkları üç ayda bir olmak üzere yılda dört olarak belirlenmesine rağmen, 2001 ve 2010 yılları arasındaki bütün ciltlerde iki sayının birlikte çıkarıldığını belirtmiştir. Her ne kadar belirtilen tarihlerden önce yayımlanmış olsa da, Fırat Üniversitesi Veteriner Fakültesi Dergisi için de bu durumun geçerli olduğu görülmektedir. Dergide yaşanan bu tür aksaklıkların Derginin yazışma adresi olarak Fırat Üniversitesi Veteriner Fakültesi Dekanlığı, Elazığ gösterilmesine karşın, basımının Ankara Üniversitesi Basımevinde yapılıyor olmasından ya da 1970'li yıllarda derginin yayın prosedürlerinin hızlı bir şekilde gerçekleştirilememesi, hakemlere yayınların posta ile gönderimi gibi nedenlerden kaynaklanabileceği düşünülebilir. İlk sayıda dergide yer alan makalelerin 11 ve 15 Kasım 1973 yılında dergi yayın kuruluna gelmesine karşın 1974 yılında sadece bir sayının basılmış olması da bu görüşü kuvvetlendirmektedir.

Derginin ilk sayısında "Başlarken" başlığı altında derginin çıkarılış amacı "Dergimiz, bölgenin hayvancılık sorunlarını ve Fakültemizin akademik faaliyetlerini dile getirmeye çalışacak ilmi bir organdır. Doğu Anadolu'da hayvancılık ile ilgili, henüz ele alınmamış, birçok inceleme ve araştırma konusu vardır" şeklinde belirtilmiştir. Dergide yayınlanmış makalelerin önemli bir kısmının Zootekni, Su ürünleri, Parazitoloji bilim alanları ile ilgili olması ve yayınlanan çalışmaların yazarlarının daha çok Fakülte kadrosunda görev alan akademisyenlerden oluşması, dergide yürütülen faaliyetlerin kuruluş amaçları doğrultusunda şekillendiğine işaret olarak kabul edilebilir. Yine aynı başlangıç yazısında yer alan, "Türkiye Bilimsel ve Teknik Araştırma Kurumu ve Devlet Planlama Teşkilatı Doğu illeri hayvancıllğını kapsayan projeleri öncelikle desteklemeli, teşvik etmelidirler. Illgili kuruluşlardan gönderilen yazılara dergimiz açıktır; onlara yer vermekten kıvanç duyacağız" șeklindeki ifadeler de derginin amaçlarını anlamak ve bu amaca ne denli hizmet edildiğinin anlamak açısından önemlidir. Nitekim dergide yayınlanan toplam 109 araştırma makalesinin 14'ünün TÜBITTAK ve uluslararası kuruluşlarca desteklenen projelerden üretilmiş olması, dördünün ise TÜBİTAK tarafindan düzenlenen toplantılarda sunulan çalışmalar olduğu anlaşılmaktadır. Buradan da yola çıkıldığında, dergide yürütülen yayın faaliyetlerinin, kuruluş amaçlarında belirtilen işlevleri yerine getirmeye, hem ülkenin ve bölgenin hayvancılık sorunlarına eğilmeye, hem de fakültenin akademik faaliyetlerine yer vermeye yönelik bir nitelik taşıdı̆̆ 1 söylenebilir.

Fırat Üniversitesi Veteriner Fakültesi Dergisinde yayınlanan toplam 140 bilimsel çalışmanın önemli bir kısmı (38 Türkçe,10 İngilizce makale ve sekiz Türkçe derleme olmak üzere toplam 56 bilimsel çalışma), Ankara Üniversitesi Veteriner Fakültesindeki öğretim elemanlarınca hazırlanmıştır. Ayrıca derginin formatı incelendiğinde, Ankara Üniversitesi Veteriner Fakültesi Dergisi ile format ve içerik açısından benzerlikler olduğu göze çarpmaktadır. Firat Üniversitesi Veteriner Fakültesinin kuruluşunda Ankara Üniversitesi Veteriner Fakültesindeki öğretim elemanlarının özverili çalışmaları ve katkıları da düşünüldüğünde, derginin yayın hayatına başlarken en büyük desteği yine Ankara Üniversitesi Veteriner Fakültesinden gördüğü söylenebilir.

Derginin dokuz yıllık yayın süresi boyunca basılmış çalışmalar bilim alanlarına göre değerlendirildiğinde sayısal olarak en fazla çalışmanın (17 adet) zootekni alanında yapıldığı görülmektedir. Bu durum yine derginin kuruluş sürecinde önemle vurgulanan "Çevre şartlarl, ekonomik ve sosyal durum göz önünde bulundurularak orijinal araştırmalar yapmak ve yetiş̧iricinin uygulamasına sunmak görevimiz olmalıdır" şeklindeki amaca ulaşmak çabasına bir gösterge olarak kabul edilebilir. Benzer şekilde kuruluş amacı, "Yurdumuz özellikle Elazı̆̆ Veteriner Fakültesinin bulunduğu Doğu Anadolu Bölgemiz iç sular balıkçıllğg ve diğer su ürünleri bakımından geniş imkanlar gösteren ve bilimsel çalışmalara hem daha müsait, hem de çok ihtiyaç gösteren bir bölgemizdir" şeklindeki ifade edilen Su Ürünleri, Balıkçılık ve Av Hayvanları Kürsüsü akademisyenleri önderliğinde yürütülen ve Fırat Üniversitesi Veteriner Fakültesi Dergisinde yayınlanan 13 bilimsel çalışmanın (sekiz İngilizce ve beş Türkçe), Fırat Üniversitesi Veteriner Fakültesi bölümlerinde ve Firat Üniversitesi Veteriner Fakültesi Dergisinde, kuruluş amaçları doğrultusunda faaliyet yürütüldüğ̈̈ne kanıt olarak gösterilebilir.

Mesleki dergilerin, mesleklerin bilimsel gelişimi yanında sosyal gelişiminde de önemli hizmetleri olduğu bilinmektedir (1). Ankara Üniversitesi Elazı̆̆ Veteriner Fakültesi Dergisinin ilk sayısından itibaren -derginin çıkış amaçlarında da belirtildiği gibi - fakültede gerçekleşen akademik değişiklik ve olaylara, veteriner hekimliği ve 
hayvancılık ile ilgili haberlere yer verildiği görülmektedir. Türkiye'de kurumlardaki arşiv kültürünün tam oturmadı̆̆ yeterli olmadığı ve bir çok bilgi ve dokümanın zaman içinde yok edildiği veya kaybolduğu düşünüldüğünde $(11,12)$, dergideki bu tür paylaşımların derginin yayımlandığı döneme ait bilgileri günümüze taşıyarak fakültenin tarihi konusunda önemli bilgileri gün ışığına çıkardığı söylenebilir.

Her süreli yayında değişen tekniğe ve yayın kurallarına göre bazı durumlarda değişikliklerin yapılma zorunluluğu olmakla birlikte, sık ve ilerde problemlere neden olabilecek değişmelerin yapılmasından da kaçınılması gerekmektedir (7). Bu bağlamda Dergide görülen biçimsel farklılıkların (Yayın kurallarındaki değişimlerin, sayfa numaralarının verilişi, sayıların belirlenmesi vb.) dergi yazı kurullarını ve yazı işlerini yöneten öğretim elemanlarının değişikliklerinden kaynaklanan görüş farklılıklarından ya da kurumsal ve sistematik bir yapının kurumda henüz yerleşememesinden kaynaklanmış olabileceği söylenebilir.

Sonuç olarak; Fırat Üniversitesi Veteriner Fakültesi Dergisinin yayınlandığı dönemde, başta Doğu Anadolu Bölgesinin ve Türkiye'nin hayvancılık sorunlarına yönelik yürütülmüş bilimsel çalışmaların bir kısmına ev sahipliği yaptığı; yayın hayatı süresince akademik çalışmalar dışında eğitsel ve mesleki bir takım yazılara da yer vermek suretiyle arşiv niteliği taşıyan bir kaynak olduğu ileri sürülebilir.

\section{Kaynaklar}

1. Aslım G, Yiğit A, Yaşar A (2011): Türk Veteriner Hekimleri Birliği Dergisinin on yıllık (2001-2010) yayın hayatı üzerine bir inceleme. Türk Veteriner Hekimleri Birliği Dergisi, (3-4), 48-52.

2. Dinçer F (1964): Türkiye'de kurulan veteriner dernekleriyle bugüne kadar olan gelişmeler. Türk Vet Hekim Der Derg, 34(11-12), 487-502.

3. Dinçer F (1965): Mecmûa-i Fünunu Baytariye ve Osmanlı Cemiyeti Ilmiyyei Baytariyesi. Türk Vet Hekim Der Derg, 35(3-4), 198-203.

4. Dinçer F (1976): Türkiye'de veterinerlik ve tarım alanında ilk süreli yayın "Vasıta- $i$ Servet" üzerinde bir inceleme. Furat Üniv Vet Fak Derg, 3(1), 66-83.

5. Dinçer F (1980): The centenary of veterinary journalism in Turkey. Firat Üniv Vet Fak Derg, 5(1), 166-179.

6. Erk N (1959): Veteriner hekimliğin ilk dernekleri, dergileri ve milletlerarası kongreleri. Türk Vet Hekim Der Derg, 29(158-159), 483-487.

7. Erk N, Dinçer F (1967): Türk Veteriner Hekimleri Derneği Dergisinin Yayın Hayatı ve 1930-1944 Yılları İndeksi. Türk Veteriner Hekimleri Derneği Yayınları, Ankara.

8. Melikoğlu Gölcü B, Osmanağaoğlu Sanal Ş (2012): Mecmua-i Fünûn-î Baytariye: Inceleme ve özetli bibliyografya. Osmanlı Bilimi Araştırmaları, 14(1), 45-88.

9. Özen A (1998): Türk Veteriner Hekimliği Dergisinin on ylllı (1989-1998) yayın hayatı üzerine bir inceleme. Türk Vet Hek Derg, 10(4), 8-11.

10. Özen A, Özgür A (1998): Türkiye'de veteriner hekimliği alanındaki eski harfli süreli yayınlar üzerinde tarihsel bir inceleme, 501-512. In: Kahya E, Şar S, Ataç A, Oğuz NY, Arda B. (Ed), V. Türk Tıp Tarihi Kongresi Bildirileri. Ankara Üniversitesi Basımevi, Ankara..

11. Öztürk R, Yerlikaya H (2001): Etlik Merkez Veteriner Kontrol ve Araştırma Enstitüsünün tarihçesi. YYÜ Vet Fak Derg, 12(1-2):59-63.

12. Tekin G (2008): Kurum tarihi yazımıyla ilgili sorunlar. Ankara Üniversitesi Türk İnkılâp Tarihi Enstitüsü Atatürk Yolu Dergisi, 42,331-340. 